\title{
A AVALIAÇÃO EDUCACIONAL EM CONTEXTOS MUNICIPAIS
}

\author{
Dirce Nei Teixeira de Freitas \\ Nataly Gomes Ovando*
}

\begin{abstract}
RESUMO: Trata-se de como municípios respondem à avaliação nacional e que uso fazem da ferramenta avaliação em suas redes. Baseia-se em estudo realizado em 10 redes escolares municipais sul-mato-grossenses com destaque no Ideb. Foram identificadas duas principais estratégias municipais: (1) incorporação seletiva e com procedimentos de adaptação e gradação das medidas nacionais, expressando forma peculiar de colaboração com a Uniâo; (2) construção incipiente de ferramentas municipais de avaliação, para atender peculiaridades e preservar autonomia municipal. No geral, o uso da avaliação está orientado para a regulação, a indução e, raramente, para as funçóes diagnóstica, formativa ou de prestação de contas pública.
\end{abstract}

Palavras-chave: Educação municipal. Política educacional. Gestão educacional. Avaliação municipal.

\section{EDUCATIONAL EVALUATION IN MUNICIPAL CONTEXTS}

ABSTRACT: In this text we discuss how local authorities respond to the national evaluation exam and how this evaluation tool is used in their school systems. The data discussed is based on studies carried out in ten municipal school systems from the State of Mato Grosso do Sul whose results, as shown by the Ideb (Education Index), are high. Two main municipal strategies were identified: (1) selective incorporation along with the use of adaptation and gradation procedures of national measures, expressing a special form of collaboration with the Union; (2) incipient construction of municipal tools for evaluation, as a means to answer for peculiarities and to preserve municipal autonomy. In general, the use of the evaluation tool is orientated towards regulation, induction, and rarely for diagnostics and formative purposes or for public accountability.

Keywords: Municipal education. Educational policy. Educational management. Educational evaluation.

\footnotetext{
* Universidade Federal da Grande Dourados, Faculdade de Educaçáo. Dourados, MS., Brasil. E-mail de contato: dircenei@terra.com.br.
} 


\title{
L'ÉVALUATION EN ÉDUCATION DANS LES MUNICIPALITÉS
}

\begin{abstract}
RÉSUMÉ: Il s'agit de la façon dont les municipalités réagissent à l'évaluation nationale de l'éducation dans leurs réseaux. On part d'une étude menée autour des dix établissements scolaires au Sud de l'état de Mato Grosso do Sul ayant eu le prix d'excellence (Ideb). Deux stratégies municipales y ont été identifiées: (1) l'incorporation sélective et des procédures d'adaptation et de classement des mesures nationales exprimant une forme particulière de collaboration avec l'État; (2) la construction naissante d'outils d'évaluation municipaux pour répondre aux particularités et préserver l'autonomie des municipalités. Dans l'ensemble, l'utilisation de l'évaluation est axée sur la régulation, l'induction et rarement sur les fonctions de dignostic, de formation ou de reddition de comptes.
\end{abstract}

Mots-clés: L'éducation dans les municipalités. La politique éducative. Gestion de l'éducation. Évaluation municipale.

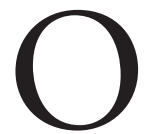

uso da avaliação como ferramenta de política e de gestão da educação básica tem crescido no Brasil sob o influxo da avaliação em larga escala de iniciativa da União, assim como das experiências avaliativas estaduais, principalmente de Minas Gerais e de São Paulo. Desde a introdução da Prova Brasil ${ }^{1}$ (BRASIL, 2005) e, mais acentuadamente, do Índice de Desenvolvimento da Educação Básica (Ideb)² (BRASIL, 2007). Nos anos 2005 e 2007, respectivamente, os municípios também se envolvem, cada vez mais, com o uso da avaliação em suas redes escolares. As características desse processo são pouco conhecidas, por se tratar de algo recente e múltiplo.

Buscamos conhecer a dimensão política do processo em redes escolares municipais que se destacaram no indicador oficial Ideb, em estado da federação cujo desempenho nos indicadores oficiais tem ficado próximo ou na média nacional. Nosso objetivo foi o de analisar estratégias municipais em face das avaliaçóes nacionais e quais são os usos da avaliação na política/gestão educacional municipal.

Este artigo baseia-se em dados e constatações de estudos exploratórios realizados, nos anos de 2009 e 2010, em 10 municípios do estado de Mato Grosso do Sul (MS) e trabalha com a amostra estabelecida pelo projeto principal. ${ }^{3}$

No universo de 78 municípios do estado, foram selecionadas 37 redes escolares que, segundo dados do Censo Escolar de 2005, atendiam a, pelo menos, 1000 alunos nos primeiros anos do ensino fundamental ( $1^{\circ}$ ao $\left.5^{\circ}\right)$. Com esse procedimento, foram deixadas de lado 41 redes de pequeno porte em razão das peculiaridades de suas condiçóes políticas, administrativas, técnicas, entre outras. No subconjunto, foram ainda selecionadas dez redes que haviam se destacado no Ideb do ano de 2007, ou por apresentarem os cinco mais elevados resultados nesse 
Índice, ou por terem conseguido as cinco maiores variações positivas do Índice no biênio 2005-2007.

Inicialmente argumentamos acerca do interesse em se investigar os usos da avaliação, comentando, a seguir, as açóes nacionais associadas à avaliação da educação básica, passando à análise das respostas municipais a essas açóes, assim como dos usos municipais da ferramenta avaliaçáo nas suas redes escolares, trazendo finalmente considerações acerca das constataçóes.

\section{Por que investigar o uso da avaliação}

O interesse pela avaliação tem sido fomentado por pesquisas realizadas em diversos países as quais encontraram nexo positivo entre a sua realização e o bom desempenho escolar. Na linha de investigação dos fatores associados à eficácia escolar, os pesquisadores apontam a avaliação da escola e o monitoramento do progresso dos alunos como mecanismos que contribuem para que: (a) haja foco no ensino e na aprendizagem; (b) haja aumento das expectativas e dos incentivos positivos; (c) gestores e docentes possam detectar e remediar rapidamente, com açóes específicas, eventuais problemas de desempenho escolar. As avaliaçóes e controles sistemáticos estariam ainda associados à ênfase no ensino de saberes básicos (leitura, escrita, matemática), considerada também um dos fatores fundamentais para o sucesso da escolarização. (REYNOLDS; TEDDLIE; SAMMONS, 2008; BRESSOUX, 2011)

Pesquisas conduzidas no Brasil não chegaram a constataçôes específicas sobre a avaliação. Todavia análises críticas da dimensão política da avaliação e dos controles da educação básica, realizadas por pesquisadores brasileiros, alertam a respeito de implicaçóes e desdobramentos da forma como essa ferramenta de política e gestão tem sido usada no Brasil. As preocupaçóes incidem principalmente sobre: o acento dado a finalidades reguladoras e indutoras em prejuízo da contribuição da avaliação para a emancipação; a difusão de óticas mercadológicas na educação; a instrumentação que propicia processos gerenciais em prejuízo da gestão democrática; a concorrência para disseminar uma concepção redutora de qualidade de ensino; a concorrência para a redução do currículo escolar ao que é mensurável; a concorrência para a centralização homogeneizante da regulação por meio de um processo normativo, pedagógico e educativo que problematiza relaçóes federativas; a prevalência do tecnicismo em favor da privatização da educação pública, entre outros. (SOUSA, 1997; BARRETO, 2001; SOUSA; OLIVEIRA, 2003; SOUSA, 2003; FREITAS, 2004; FREITAS, 2005; GATTI, 2007)

De modo geral, as referidas análises concordam em que a prática da avaliação educacional, no país, é uma problemática com amplo leque de questóes 
postas à pesquisa em educação. Entre tantas questôes estão a dos usos da avaliação e de como atores subnacionais respondem às açôes nacionais de avaliação e de monitoramento educacionais. Estas questóes desafiam pesquisadores do campo da análise de políticas públicas educacionais, principalmente aqueles que cultivam o entendimento de que a política/gestão da educação básica não será compreendida com abordagens circunscritas a atores posicionados ao centro da organizaçáo estatal federativa brasileira.

Primeiro porque o espaço político que conforma a educação escolar no Brasil é o de complexas e conflituosas relaçóes entre entes federados autônomos, interdependentes e coordenados pela Uniāo. (ABRÚCIO, 2006) Nesse contexto, a organização político-administrativa da educação, inscrita na norma vigente, requer regime de colaboração federativa no governo da educação básica. No entanto, práticas pouco colaborativas e/ou competitivas entre entes federativos, além de vários outros obstáculos à efetivação do regime de colaboração, tornam multicêntrico o governo desse nível de educação escolar no Brasil, impedindo a existência de um sistema nacional de educação. (CURY, 2008; SAVIANI, 2010; CRUZ, 2010) Assim, a regulação nacional da educação básica configura-se na dialética das relaçóes intergovernamentais federativas e das relaçóes internacionais.

A regulação nacional consiste em modo de coordenação dos sistemas de ensino por meio de regras que orientam seus funcionamentos e também dos reajustamentos das ações dos diversos atores que, resultando de interaçóes de diferentes reguladores, se caracteriza como multirregulação. (BARROSO, 2005) Nesse contexto, mesmo que o Executivo nacional tenha força para delinear e coordenar a política nacional de educação, mediante indução e dispositivos centralizados de regulação, os Executivos subnacionais podem e, geralmente, empreendem iniciativas próprias de política e gestão educacionais no exercício de sua autonomia relativa. Nesse sentido, são ilustrativas as iniciativas estaduais e municipais, entre outras, de avaliação educacional que surgem ao tempo em que o governo federal amplia o seu aparelho avaliativo. (FREITAS, 2012)

Outra razão para abordagens menos restritas a atores posicionados ao centro do Estado federal diz respeito ao próprio conceito de "políticas educacionais" como políticas públicas.

As políticas públicas se definem como o Estado em ação em cada momento histórico, em cada conjuntura. Ação essa que se produz no amplo espaço político prefigurado na dialética da relação entre a reprodução global das sociedades e a reprodução de cada setor específico para os quais políticas públicas são concebidas, formuladas, implementadas. Logo, as políticas públicas refletem relaçóes de poder e dominação, articulando-se com o projeto mais global da sociedade, construído por forças sociais que têm poder de voz e decisão junto ao Estado e governo, e com o referencial normativo setorial. Este último expressa a 
representação dominante no setor onde grupos que o integram lutam por inscrever suas demandas na agenda estatal e governamental. Assim, as políticas expressam formas de conhecimento e interpretação da realidade que são próprias dos atores sociais que buscam conquistar e manter hegemonia na esfera da ação do estado. (JOBERT; MULLER, 1987) Com as aceleradas transformaçóes sociais no mundo contemporâneo, o referencial global e o setorial das políticas educacionais do Estado Nacional não mais se definem circunscritas a este ator, senão na dialética de relaçóes "multiescalares". Lembra-nos Dale (2010) que contemporaneamente a construção da educação - que compreende o delineamento de suas políticas - se dá por meio de combinaçóes e coordenação de atividades, atores/agentes e escalas supranacional, nacional, subnacional.

Desse modo, a formulação e a implementação das políticas educacionais resultam de processos complexos interligados, imbricados ou sobrepostos, em interseção, paralelos, contrários, análogos, nos quais múltiplos atores se inter-relacionam (PALUMBO, 1989) e o fazem cooperativa e/ou competitivamente.

Entre os muitos atores, as escolas se constituem espaços em que se concretizam as definiçóes sobre políticas públicas no qual, como argumentou Lima (2002), os atores não agem somente com base em regras estabelecidas a priori, mas exercitam autonomia política, ensaiam açóes pontuais, praticam “infidelidades normativas" ou resistências mais ou menos clandestinas.

Em resumo, as políticas educacionais brasileiras emergem de situaçóes múltiplas, multicêntricas, envolvendo transações entre vários planos (local, municipal, estadual, regional nacional, internacional e transnacional). Diferentes visóes, interesses, decisôes, açôes, comportamentos, atitudes e meios operados produzem políticas como mesclas de cristalizações, flexibilizações, transgressões e criações de distintos atores (idealizadores, condutores, gestores, executores).

Considerando isso, o pesquisador interessado na compreensão da avaliação como ferramenta da política/gestão educacional tem bons motivos não só para se ocupar da questão de sua inserção nas políticas nacionais como, também, de como tais políticas se materializam no extenso território brasileiro e na sua complexa sociedade. Consideramos que investigaçóes exploratórias, ainda que limitadas, podem trazer contribuiçóes para ampliação do conhecimento a respeito.

\section{Usos da avaliação no Brasil}

A educação escolar universal e de qualidade ainda é um bem jurídico inalcançado por grande parte da população brasileira, uma vez que a sua efetivação tem sido historicamente protelada. Por isso e por motivaçóes contemporâneas que levam as sociedades a enfatizar a importância da educação escolar, um dos 
principais imperativos brasileiros, na atualidade, é o da conquista de avanços educacionais.

No caso brasileiro, está patente que a tarefa estatal em educação escolar, posta pelas múltiplas necessidades sociais, requer, fundamentalmente, equacionamentos de ordem estrutural. O enfrentamento dessa tarefa, pelo Estado, tem se dado mais resolutamente nos últimos 15 anos, de sorte que os avanços são consideráveis como ponderou Oliveira (2007). Mas, esse enfrentamento tem se dado referenciado em projeto de reprodução global da sociedade comprometido com a reestruturação capitalista. Neste processo, os Estados são pressionados diferentemente a responderem a imperativos econômicos, políticos, culturais (JESSOP, 1998; THERBORN, 2000; ZACHER, 2000; MÜREKKEP, 2002), ganhando destaque o ideário neoliberal. (MORAES, 2000) No caso do Brasil, políticas neoliberais coexistem com a explicitação de demandas sociais no contexto de construção e consolidação das instituições democráticas, de modo que o Estado precisa coordenar complexas demandas internas e externas.

Nesse contexto, os equacionamentos dos desafios nas políticas públicas não têm sido incisivos no tocante aos problemas estruturais da área social. Por mais que recursos sejam destinados a essa área, que programas sejam implementados, que avanços socioeconômicos sejam inegáveis na última década, os indicadores sociais mostram que ainda há muito por fazer para a necessária redução de desigualdades. $\mathrm{Na}$ educação, a ótica economicista postula fundamentos que preceituam redução e eficiência dos gastos e eficácia do ensino. Além do financiamento educacional reconhecidamente insuficiente, diversos problemas sociais que afetam a educação escolar não são enfrentados de forma satisfatória, além do que pesa a complexidade do contexto político, institucional, governativo e administrativo, ao que se somam fatores culturais. Assim, em uma sociedade que reclama, mas não investe suficientemente na educação escolar de qualidade para todos, o Estado tem se mostrado incapaz de cumprir a contento suas tarefas, de superar limitaçóes governativas e contar com a convergência de esforços. Desse modo, a ação estratégica do Estado brasileiro, com vistas a gerar e universalizar qualidade na educação escolar básica, acabou por estabelecer como uma das prioridades nacionais o alcance de um mínimo de melhoria do ensino expresso no Ideb.

O Ideb é um indicador educacional sintético (FERNANDES, 2007) calculado com base em dois indicadores: o indicador de rendimento escolar, obtido com dados do Censo Escolar sobre fluxo escolar (aprovação, reprovação e evasão); e no indicador de desempenho cognitivo dos alunos em avaliações nacionais (Prova Brasil e Saeb) expresso em níveis de proficiência em conhecimentos, competências e habilidades relativos aos componentes curriculares avaliados, ou seja, Língua Portuguesa (leitura) e Matemática (cálculo e resolução de problemas). 
O Ideb foi instituído pelo Decreto n. 6.094/2007 (BRASIL, 2007) como uma das principais ferramentas do Plano de Metas "Compromisso Todos pela Educação", com o qual a União estabeleceu 28 diretrizes para promoção da qualidade do ensino no país. Essas diretrizes sumariamente contemplam:

- Estratégia: ação cooperativa entre entes federados e participação da sociedade.

- Prioridade comum: melhoria dos resultados (rendimento e aproveitamento escolares).

- Determinaçóes: foco na aprendizagem; prazo para a alfabetização fixado para os 08 anos de idade; avaliaçóes periódicas da alfabetização; monitoramento da permanência e aproveitamento escolares por diversos meios; promoção da permanência, do rendimento e do aproveitamento escolares por meio de diversas açóes e práticas; incremento curricular nos aspectos éticos, artísticos e de educação física; promoção de equidade escolar, ampliaçáo do atendimento na educação infantil e reposição do direito à educação de jovens e adultos.

- Geração de condiçóes: melhoria das condições profissionais, cobrindo aspectos como os de formação, carreira, salário; criação e melhoria de condições político-institucionais e administrativas (avaliação, monitoramento, divulgação de indicadores educacionais, incremento da gestão escolar na dimensão técnica e política, gestão pública participativa, continuidade e memória das açôes, integração de programas sociais, açóes culturais e socioeducativas, governança educacional referida no Ideb e parceria com vistas a soluções infraestruturais).

O Ideb tem sido uma das mais utilizadas ferramentas da União na coordenação nacional da educação básica, uma vez que lhe permite:

a) Articular ferramentas de medida, avaliação e informação de que dispunha desde os anos 1990, canalizando-as para as funçóes de indução e regulação da política de melhoria da qualidade do ensino no País;

b) Mapear a situação das redes e unidades escolares, identificando os seus patamares no ano de 2005, com base nos quais pode projetar avanços mínimos que traduziu em metas bienais a serem alcançadas até 2021;

c) Fixar parâmetro médio nacional da qualidade de ensino, nos indicadores priorizados, expresso na média 6,0 que, referida no Programa de Avaliação Internacional Comparada (Pisa), estreita conexóes da política educacional interna com "guióes" internacionais; 
d) Precisar compromissos de melhoria a serem atendidos pelos entes subnacionais, estabelecendo em que melhorar, quanto (ao menos), em que ritmo (mínimo), em que prazo (máximo).

Está claro que a qualidade de resultados a se alcançar na educação escolar básica brasileira, até o início da próxima década, deve ser, pelo menos, a que está projetada pelo Ideb. Com este Índice o mínimo em termos de resultados do ensino está fixado nacionalmente.

A restrita concepção de qualidade do Ideb expressa prioridade à eficiência e à eficácia do ensino fundamental e médio, com o que o governo federal enfatiza mediações técnicas e gerenciais no equacionamento da complexa coordenação federativa da prestação dessas etapas de escolarização.

Com o Ideb, a União criou condiçôes para empreender bienalmente o monitoramento do ensino fundamental e médio no país, localizando avanços, estabilidades, defasagens, involuçôes. Isso tem propiciado ao governo federal condiçóes para a regulação centralizadora favorecida pela articulação do Ideb com outras ferramentas da política e gestão educacionais, destacadamente a gestão de recursos financeiros concernentes à função de suplência e de apoio técnico da União. Assim, o mesmo Decreto n. 6.094/2007 instituiu o Plano de Açóes Articuladas (PAR) - uma ferramenta de gerenciamento remoto articulada ao Ideb, cuja aceitação pelos entes subnacionais, tornou-se condição obrigatória para que pudessem contar com a suplência financeira e apoio técnico da Uniâo. A adesão formal dos entes subnacionais ao PAR avalizou os nexos entre diretrizes estabelecidas, monitoramento instrumentado pelo Ideb e planejamento para o gerenciamento de açóes financiadas supletivamente. Com esse encaminhamento, o governo federal ampliava os seus canais para fazer chegar à escola mais das suas tecnologias de controle remoto. Entretanto, pesquisas de Antunes; Vivian (2010), Batista (2011), Durli; Nardi; Scheneider (2011), Farezena; Schuch; Mosna (2011), entre outras, mostraram as dificuldades e os limites da implantação do PAR que expressam distanciamentos entre o ato formal e a efetiva adesão a essa ferramenta por parte de entes federativos subnacionais.

O conjunto de ferramentas que o referido Decreto articulou, suas lógicas e seus vínculos são expressóes práticas do significado que o MEC tem dado ao "sistema nacional articulado de educação". Esse entendimento foi transposto para o Projeto de Lei n. 8.035/2010 (BRASIL, 2011), que tratava do Plano Nacional de Educação (PNE) para o decênio 2011-2020, de iniciativa do MEC.

Nesse conjunto de iniciativas do governo federal, a avaliação apresentou-se articulada a estratégias e ferramentas indutoras e reguladoras. Até então os dados avaliativos não haviam sido suficientemente levados em conta pelos governos e escolas, como observou Gatti (2007). Todavia, ao se apresentar centrada no 
desempenho cognitivo do estudante em testes, a avaliação em larga escala estimulou, segundo Gatti, uma representação reducionista sobre qualidade da educação na sociedade brasileira, que o Ideb pouco amplia.

Embora com limitaçóes, configura-se o Estado-avaliador que tende a assumir com destaque o papel de estabelecer alvos a serem atingidos e a organizar um sistema de avaliação e de monitoramento dos resultados. (BARROSO, 2005) Esse Estado aumenta a centralização do controle dos resultados dos sistemas de ensino e da oferta de insumos e induz entes federativos a se preocuparem com a autorregulação, ou seja, com o acionamento de dispositivos de regulação própria. Assim, o lócus da avaliação e o controle do avaliador tornaram-se ponto de tensão nas relaçôes federativas que, longe de ser atenuado, foi acentuado quando o governo federal estendeu o controle de resultados até as unidades escolares.

O Ideb acentua o foco na quantidade, na comparação e competição, e realça uma restrita concepçáo de qualidade que pode ter consequências redutoras dos fins e meios da educação. Seu uso como parâmetro para aferir a melhoria da aprendizagem tem sido criticado, bem como o fato de que seja divulgado mais como ranking do que mapeamento das escolas que precisam de ajuda. Desse modo, o Ideb contribui para a difusão na educação de racionalidade econômica, contábil, técnica, positivista, pragmática, gerencialista, prestando-se ao surgimento de políticas e de avaliaçóes orientadas pelos interesses dominantes na reestruturação capitalista. Frente a isso, no setor de educação emergem demandas para o estabelecimento de um sistema nacional de avaliação educacional que considere também fatores extraescolares, insumos educacionais, localização das escolas, que abarque educação básica e superior públicas e privadas, tendo como horizonte contribuir, por meio da educação, para minorar desigualdades sociais. (DOURADO, 2011)

\section{Contextos municipais}

Na sequência, procuramos analisar o que vem ocorrendo nas 10 redes escolares componentes da amostra deste estudo: Campo Grande, São Gabriel do Oeste, Aparecida do Taboado, Chapadão do Sul e Naviraí que apresentaram os mais elevados resultados no Ideb do ano 2007. Bonito, Paranhos, Amambai, Paranaíba e Bela Vista que registraram as maiores variaçóes positivas do Ideb no biênio 2005-2007. (BRASIL, 2007)

Os municípios são, na maioria, de pequeno porte e há poucos anos emancipados, com crescimento populacional e com indicador econômico - Produto Interno Bruto (PIB) per capita - abaixo da média estadual e nacional. No ano de 2000, metade deles apresentava um Índice de Desenvolvimento Humano 
Municipal (IDH) inferior ao do estado de Mato Grosso do Sul (MS) e do Brasil (Tabela 1).

\section{Tabela 1}

Ano de emancipação, área, população, PIB per capita

e IDH-M, por município da amostra

\begin{tabular}{l|c|c|cc|c|cc}
\hline \multirow{2}{*}{$\begin{array}{l}* \\
\text { Município }\end{array}$} & \multirow{2}{*}{$\begin{array}{c}\text { Ano de } \\
\text { emancipação }\end{array}$} & \multirow{2}{*}{$\begin{array}{c}\text { Taxa de } \\
\text { urbanização }\end{array}$} & \multicolumn{2}{c|}{ População } & \multicolumn{2}{c|}{ PIB } & \multicolumn{2}{c}{ IDH-M 2000 } \\
\cline { 4 - 8 } & & $\mathbf{2 0 0 7}$ & $\mathbf{2 0 1 0}$ & $\begin{array}{c}\text { per capita } \\
\text { (RS) }\end{array}$ & $\begin{array}{c}\text { Pontuação } \\
\text { Ranking } \\
\text { estadual }\end{array}$ \\
\hline Aparecida do Taboado & 1948 & 88,53 & 19.819 & 22.320 & 14.497 & 0,763 & $19^{\circ}$ \\
Campo Grande & 1899 & 98,67 & 724.524 & 786.797 & 12.346 & 0,814 & $2^{\circ}$ \\
Chapadão do Sul & 1987 & 81,59 & 16.193 & 19.648 & 27.816 & 0,826 & $1^{\circ}$ \\
Naviraí & 1963 & 91,94 & 43.391 & 46.424 & 12.269 & 0,751 & $32^{\circ}$ \\
São Gabriel do Oeste & 1980 & 86,13 & 20.524 & 22.203 & 21.126 & 0,808 & $3^{\circ}$ \\
Amambai & 1948 & 56,76 & 33.426 & 34.730 & 9.132 & 0,759 & $22^{\circ}$ \\
Bela Vista & 1908 & 80,02 & 22.868 & 23.181 & 7.454 & 0,755 & $27^{\circ}$ \\
Bonito & 1948 & 79,91 & 17.275 & 19.587 & 9.111 & 0,767 & $18^{\circ}$ \\
Paranaíba & 1857 & 88,03 & 38.969 & 40.192 & 10.266 & 0,772 & $14^{\circ}$ \\
Paranhos & 1987 & 49,13 & 11.092 & 12.350 & 5.004 & 0,676 & $75^{\circ}$ \\
Estado MS & - & 84,08 & 2.078 .001 & 2.449 .024 & 12.411 & 0,778 & - \\
Brasil & - & 81,25 & 169.799 .170 & 190.755 .799 & 13.515 & 0,766 & - \\
\hline
\end{tabular}

Fontes: IBGE (2010), Confederação Nacional dos Municípios (2010) e PNUD (2010).

Campo Grande e São Gabriel do Oeste localizam-se na mesorregião Centro-Norte do estado; Aparecida do Taboado, Chapadão do Sul e Paranaíba na mesorregião Leste. Nessas mesorregiooes destaca-se a força da atividade econômica agropecuária. Campo Grande, capital do estado, se destaca também no setor de serviços. Essas mesorregióes concentram a área de maior arrecadação fiscal do MS, sendo as mais ricas em termos de PIB per capita. Os municípios com os mais elevados PIB (Chapadão do Sul e São Gabriel do Oeste) apresentavam também as melhores condições demográficas e sociais. São Gabriel do Oeste, Chapadão do Sul e Campo Grande apresentam a menor taxa de analfabetismo entre os $10 \mathrm{mu}$ nicípios selecionados. Esses municípios apresentavam, no ano de 2000, um Índice de Desenvolvimento Humano (IDH) superior ao do Estado de Mato Grosso do Sul (de 0,769) e, também, do Brasil (0,766).

Os municípios de Bela Vista, Bonito, Naviraí, Amambai e Paranhos localizam-se na mesorregião Sudoeste do estado, compondo a região de influência do município de Dourados (Grande Dourados), tendo a agricultura e pecuária como principais atividades econômicas. Em Bela Vista e Paranhos destaca-se a atividade pecuária e em Bonito a atividade turística é expressiva. Os municípios com os piores PIB per capita em 2007, Paranhos e Amambai, apresentavam também altas taxas de analfabetismo e IDH-M inferior aos demais municípios da amostra. Esses municípios concentram grande parte de sua população na área rural, o que 
pode ser visto como um fator de contexto relevante para compreender os seus desempenhos educacionais.

Das 10 redes escolares municipais da amostra, nove possuíam, em 2010, entre seis a 15 estabelecimentos que ofereciam o ensino fundamental. Somente a rede de Campo Grande possuía maior quantidade de estabelecimentos (93) com oferta desse ensino. De modo geral os estabelecimentos municipais de ensino localizam-se em periferias urbanas ou em área rural, onde se concentra uma população socialmente desfavorecida.

No tocante à população atendida, metade das redes escolares tinha expressiva população rural, para a qual o atendimento não estava satisfatoriamente equacionado. Duas redes ofereciam educação escolar indígena a populaçóes de aldeias e enfrentavam dificuldade no atendimento a indígenas residentes nas periferias urbanas. Três redes atendiam também populaçóes migrantes paraguaias, enfrentando dificuldades relativas ao idioma. Em todas as redes as taxas de matrículas cresceram expressivamente em quase toda a primeira década dos anos 2000 e as taxas de aprovação escolar melhoraram (Tabela 2).

\section{Tabela 2}

Indicadores do ensino fundamental ( $1^{\circ}$ ao $5^{\circ}$ ano $)$ nas redes escolares municipais da amostra

\begin{tabular}{l|ccccc|c}
\hline \multirow{2}{*}{ Municípios } & $\begin{array}{c}\text { Matrículas } \\
\text { no EF }\end{array}$ & $\begin{array}{c}\text { Taxa total de } \\
\text { distorção no } \\
\mathbf{5}^{\mathbf{0}} \text { ano }\end{array}$ & $\begin{array}{c}\text { Taxa de } \\
\text { aprovação }\end{array}$ & Ideb & $\begin{array}{c}\text { Taxa de docentes } \\
\text { licenciados }\end{array}$ & $\begin{array}{c}\text { Taxa de variação } \\
\text { dos gastos com EF } \\
\mathbf{2 0 0 5 - 2 0 0 8}\end{array}$ \\
\cline { 2 - 5 } & \multicolumn{7}{c}{$\mathbf{2 0 0 7}$} & & & 136,06 \\
Aparecida do Taboado & 1.036 & 25 & 88,6 & 4,4 & 90,38 & 114,52 \\
Campo Grande & 39.183 & 20,5 & 90,8 & 5,1 & 91,28 & 94,28 \\
Chapadão do Sul & 1.183 & 23,1 & 86,5 & 4,4 & 82,69 & 151,14 \\
Naviraí & 2.447 & 24 & 86,9 & 4,4 & 60,6 & 120,19 \\
São Gabriel do Oeste & 1.294 & 21,3 & 92,6 & 4,9 & 79,45 & 92,99 \\
Amambai & 2.683 & 40,8 & 75 & 3,9 & 59,82 & 104,08 \\
Bela Vista & 1.598 & 31,3 & 84,6 & 3,5 & 55,71 & - \\
Bonito & 1.601 & 42,5 & 79,5 & 3,9 & 67 & 85,67 \\
Paranaiba & 1.417 & 22 & 89,2 & 4,4 & 80 & - \\
Paranhos & 1.629 & 38,7 & 79 & 4,3 & 42,55 & \\
\hline
\end{tabular}

Fontes: Brasil. Mec. Inep (2012); Lima (2011).

Legenda: (-) dados indisponiveis.

Em quatro redes as taxas de distorção idade/ano eram altas e as de aprovação mostravam que o mecanismo da reprovação persistia em todas as redes. $\mathrm{O}$ Ideb de 2007 de três redes estava abaixo da média nacional (4,2). (INEP, 2012) As taxas de docentes com adequada formação inicial eram baixas em metade das redes. A variação da elevação dos gastos reais com o ensino fundamental, no período 2005-2008, era expressiva nas oito redes para as quais obtivemos esse dado. 
A institucionalização das redes escolares apresentava-se, em 2010, mais evoluída no município de Campo Grande, ainda que outros quatro municípios contassem com sistema próprio de educação, Conselho Municipal de Educação (CME), Secretaria Municipal de Educação (SME), Plano Municipal de Educação (PME), conselhos gestores da merenda escolar e do Fundo de Manutenção e Desenvolvimento da Educação Básica e de Valorização dos Profissionais da Educação (Fundeb), estabelecimentos escolares com organização própria, plano de carreira e remuneração docente, entre outros. Metade das redes ainda não possuía os seus respectivos PMEs e duas náo haviam organizado sistemas próprios, seguindo a normativa estadual.

Os principais desafios das redes escolares, segundo seus gestores, eram os de formação inicial e continuada dos professores, regularização do fluxo escolar, melhoria do desempenho cognitivo dos alunos e atendimento às diversidades existentes em suas redes.

No conjunto das redes observadas encontramos preocupação com os indicadores oficiais relativos à qualidade do ensino, principalmente com o Ideb, havendo iniciativas de avaliação.

\section{Incorporação das avaliações nacionais}

Constatamos que, com a Prova Brasil, o Ideb e o PAR as redes escolares municipais passaram a fazer uso externo e interno dos resultados das avaliaçóes.

Um dos usos de tipo externo consiste na divulgação dos resultados nos meios de comunicação local com finalidades publicitárias, emuladoras, motivadoras. As divulgaçóes ocorrem sempre que os resultados sáo positivos, fazendo destaque a açóes realizadas pelas SMEs e às escolas que obtiveram os melhores resultados na rede. Encontramos casos em que estas são premiadas em solenidades públicas, o que também é divulgado na imprensa. Em nenhum caso as divulgaçóes têm caráter de prestação de contas públicas das realizaçôes educacionais municipais, nem propósito de crítica ou denúncia sobre condiçóes de trabalho, políticas nacionais ou municipais de educação ou mesmo sobre as avaliações.

Constatamos que o uso interno das avaliaçóes nacionais - ou seja, na, pela e para a própria rede - ocorria de diversas maneiras, principalmente por meio de: estudo dos resultados pelos gestores e docentes; discussão dos resultados entre pais e mestres; realização de atividade de formação continuada programada a partir das evidências trazidas pelas avaliaçóes nacionais; acompanhamento pedagógico com base nas evidências trazidas pelas avaliaçôes. Todavia, essas iniciativas eram eventuais e predominantemente assistemáticas. 
Quatro das redes escolares discutiram os resultados das avaliaçóes na Secretaria de Educação, cinco redes os discutiram com o CME, seis com os diretores escolares, quatro com os coordenadores pedagógicos e duas com o Conselho Escolar. Segundo dirigentes e gestores das SMEs e das unidades escolares, essas discussões orientaram decisões políticas e ações implementadas.

$\mathrm{Na}$ escola, a discussão dos resultados das avaliaçóes com vistas a decidir açôes a realizar não estava estabelecida como prática que envolvesse alunos e pais. Em quase todas as redes era a SME quem decidia quais açóes seriam executadas em face dos resultados avaliativos e do Ideb. Com esse intuito as equipes pedagógicas de cinco Secretarias de Educação estudaram os resultados das avaliaçóes nacionais e oito redes municipais programaram a formação continuada.

Em todas as redes, dirigentes e gestores se mostraram convictos de que ações de formação de professores informadas pelas avaliações redundam em bom desempenho dos alunos nas provas nacionais. Os temas abordados nas ações de formaçáo continuada indicam essa preocupação, mas não só, tratam de questóes mais amplas. Os mais frequentemente encontrados foram: avaliação da aprendizagem, produção de texto, educação matemática, educação especial, organização do trabalho pedagógico; o processo de aprendizagem, o projeto pedagógico docente.

Nove redes escolares vinham usando as informaçóes disponibilizadas pelas avaliaçóes nacionais para orientar as atividades escolares de recuperação paralela dos alunos com dificuldade na aprendizagem. Todavia, o uso dos resultados para fins de gestão da rede aparece como o principal. $\mathrm{Na}$ maioria das SMEs as avaliaçóes nacionais são percebidas, principalmente, nas funçóes de indução e regulação, ou seja, fundamentalmente como ferramenta da União para controlar e coordenar os sistemas municipais e estaduais de ensino. As tentativas de apropriação municipal para promoção do ensino e da aprendizagem nas escolas são incipientes, episódicas, pontuais e superficiais.

Observamos que os usos dos indicadores de fluxo escolar e de desempenho cognitivo dos alunos (Ideb) permitiram aos administradores municipais formar uma imagem das suas redes escolares, situá-las em relação a outras redes, posicionar cada escola na própria rede. Quando positivos, os indicadores serviram como elementos de diálogo e estímulo intrarrede. Em situação inversa, os indicadores serviram como elementos de cobranças, pressóes, negociaçóes e controles, entre governantes, dirigentes e gestores educacionais, gestores e docentes, professores e alunos, atores escolares e pais de alunos.

As avaliaçóes nacionais e o monitoramento têm concorrido para que a política e a gestão municipais se reorganizem, propiciando açóes de estudo, acompanhamento, orientação e discussão voltados para resultados das avaliaçóes. Um aspecto dessa tendência tem sido o avolumar de tarefas e preocupaçóes atinentes à avaliação e monitoramento de resultados, o que modifica a atuação dos coordena- 
dores pedagógicos, que passam a interagir com professores, pais, alunos e gestores das Secretarias de Educação com o intuito de gerar melhores resultados.

\section{Construção de iniciativas próprias}

Encontramos também nas redes escolares iniciativas próprias de avaliação do ensino fundamental nas modalidades informal e formal, que tanto podem ter origem na SME quanto na unidade escolar.

As iniciativas informais têm curso nos processos interativos cotidianos entre atores dos quadros da SME, destes com atores escolares e entre estes últimos. Essas iniciativas se dão por meio de observaçóes, conversas, encontros, reuniôes realizadas assistematicamente. Geralmente os avaliadores quase não têm preocupação e cuidado de ordem técnica e não há regras preestabelecidas, nem registros, assim como consequências públicas ou continuidade assegurada. Somente relatos dão fé da existência dessas iniciativas, mas foram reportadas por todos os entrevistados.

Entre as iniciativas informais das Secretarias de Educação encontramos: (a) reuniōes avaliativas internas; (b) reuniōes com diretores escolares; (c) reuniōes com coordenadores pedagógicos; (d) reunióes realizadas com a comunidade escolar; (e) encontros da equipe pedagógica da Secretaria Municipal de Educação com diretor escolar, coordenador pedagógico e professor para estudar os casos de rendimento e aproveitamento escolares insatisfatórios; (f) visitas escolares com fins de observação da gestão e do ambiente escolares.

Em metade das redes da amostra verificamos que as escolas aproveitam as reuniốes pedagógicas e as assembleias de pais para avaliaçốes informais, cuja frequência e finalidade ficam a juízo dos coordenadores pedagógicos e dos diretores escolares.

As iniciativas informais de avaliação têm caráter participativo e, quando realizadas na escola, geralmente propiciam o envolvimento dos atores escolares e, por vezes, de pais nas tomadas de decisóes.

$\mathrm{Na}$ modalidade formal, a avaliação é realizada de forma sistemática e a intervalos preestabelecidos, utilizando-se diversos procedimentos e instrumentos consoantes a regras fixadas, havendo registros, divulgação de resultados e consequências públicas.

Nessa modalidade, Ovando (2011) encontrou várias iniciativas das SMEs: avaliaçóes diagnósticas; simulados preparatórios para a Prova Brasil; levantamentos precedendo a Provinha Brasil; avaliação da escola; e aplicação de provas para avaliação do desempenho cognitivo dos alunos. Esta última foi encontrada 
em quatro redes e somente em duas delas os registros estão disponíveis ao público (Tabela 3).

\section{Tabela 3}

Avaliação de desempenho do aluno do ensino fundamental de iniciativa de municípios de Mato Grosso do Sul (1999-2009)

\begin{tabular}{cccccc}
\hline Municípios & Avaliação & $\begin{array}{c}\text { Ano de } \\
\text { criação }\end{array}$ & $\begin{array}{c}\text { Ano } \\
\text { avaliado }\end{array}$ & $\begin{array}{c}\text { Componentes } \\
\text { curriculares avaliados }\end{array}$ & Formulação \\
\hline Amambai & Prova Amambai & 2007 & $3^{\circ}$ & $\begin{array}{c}\text { Língua Portuguesa } \\
\text { Matemática }\end{array}$ & $\begin{array}{c}\text { Secretaria Municipal } \\
\text { de Educação }\end{array}$ \\
\hline Bonito & $\begin{array}{c}\text { Projeto de } \\
\text { Avaliação } \\
\text { Diagnóstica }\end{array}$ & 2005 & $1^{\circ}$ ao $9^{\circ}$ & $\begin{array}{c}\text { Língua Portuguesa } \\
\text { Matemática }\end{array}$ & $\begin{array}{c}\text { Secretaria Municipal } \\
\text { de Educação }\end{array}$ \\
\hline $\begin{array}{c}\text { Campo } \\
\text { Grande }\end{array}$ & Promover & 1999 & $1^{\circ}$ ao $8^{\circ}$ & $\begin{array}{c}\text { Língua Portuguesa } \\
\text { Produção de Texto } \\
\text { Matemática }\end{array}$ & $\begin{array}{c}\text { Pecretaria Municicipal } \\
\text { de Educação } \\
\text { Técnicos externos }\end{array}$ \\
\hline Naviraí & $\begin{array}{c}\text { Avaliação } \\
\text { externa }\end{array}$ & 2005 & $3^{\circ}, 5^{\circ}$ e $8^{\circ}$ & $\begin{array}{c}\text { Língua Portuguesa } \\
\text { Matemática }\end{array}$ & $\begin{array}{c}\text { Professores } \\
\text { Secretaria Municipal } \\
\text { de Educação }\end{array}$ \\
\hline
\end{tabular}

Fonte: Ovando (2010).

Os gestores de quatro redes escolares (Amambai, Bonito, Campo Grande e Naviraí) acreditam que a avaliação do desempenho cognitivo dos seus alunos é uma ferramenta capaz de contribuir para a promoção da qualidade da educação escolar municipal, em especial da própria política educacional municipal. As avaliaçóes realizadas pela União náo bastam, pois as consideram incapazes de trazer informaçôes sobre as peculiaridades locais.

Mas, as redes não dispóem de conhecimento, experiência e condições (técnicas, administrativas, financeiras) que lhes permitam organizar e sustentar um aparato próprio de avaliação que seja confiável, adequado, rigoroso e inovador em relação às iniciativas da União. Assim, as iniciativas dos atores municipais são incipientes, rudimentares, ensaios de reprodução do pouco que conhecem das iniciativas nacionais.

Somente a iniciativa da rede de Campo Grande se mostrou consistente. Este município tem assegurado condições financeiras, técnicas e administrativas para a realização continuada dos ciclos de avaliação, assim como tem conseguido fazer chegar às escolas os resultados das aferiçôes, as interpretaçóes, orientaçôes, recomendaçóes e sugestôes. Há indicativos de que a iniciativa de avaliação desta rede tem consequência na formulação e implementação de políticas educacionais municipais e escolares. 
Entre as dificuldades, problemas e limitaçóes enfrentados pelas redes que organizaram avaliação própria e se empenham no monitoramento do ensino fundamental estão, principalmente, a escassez de recursos financeiros, a falta de rigor metodológico e dificuldades de ordem política na recepção e apropriação da avaliação pela comunidade escolar. Para minorar esse problema as redes preocupam-se em fazer com que a avaliação seja compreendida pela comunidade escolar, envolvendo professores na elaboração dos itens das provas municipais e discutindo os resultados das próprias avaliaçōes em reuniōes. Mesmo com limitaçóes, essas iniciativas municipais informam o monitoramento do ensino e a formação continuada dos docentes.

\section{Finalidades dos usos municipais da avaliação}

As avaliaçóes encontradas nas redes são usadas para fins de regulação e de indução, em poucos casos encontramos seu uso formativo e para fins de diagnóstico.

O uso para fins de regulação ocorre quando práticas informais e formais de avaliação são encaminhadas com a pretensão de ajustar o desempenho das escolas a padróes aceitáveis, segundo os parâmetros fixados pela União. A avaliação, nesses casos, visa a regularidade e a conformidade da escola com o que dela se espera.

$\mathrm{Na}$ função de regulação, a avaliação incide sobre desempenho e produtividade, buscando confrontar intervençôes com resultados obtidos examinando sua eficiência e eficácia. Com essa tônica, a avaliação estimula a competição entre avaliados, privilegia o controle dos resultados escolares e propicia controles direcionados aos executores do ensino.

Esse uso da avaliação nas redes está associado ao entendimento, que começa a se estabelecer nas Secretarias Municipais de Educação, de que a melhoria do ensino depende, principalmente, de medidas gerenciais baseadas em dados objetivos sobre desempenhos dos atores envolvidos.

A avaliação pode ser usada para levar atores a adotarem determinadas orientaçôes, práticas e ferramentas; para persuadir e incutir lógicas, suscitar disposiçóes favoráveis a um projeto; inspirar mudanças. Nas redes observadas, a avaliação tem sido usada para induzir, principalmente, a política de melhoria da qualidade do ensino fundamental no formato que lhe dá a esfera municipal, o qual aponta para a reprodução local da lógica da gestão por resultados. Nesse sentido, a avaliação tem se prestado mais à introdução de práticas gerenciais na gestão escolar do que à efetivação da gestão democrática. 
Na perspectiva gerencial, os usos da avaliação têm ensejado maior presença das Secretarias de Educação junto às escolas, concorrendo para o trabalho conjunto entre seus gestores e coordenadores pedagógicos. Isso tem induzido mudança no papel do coordenador pedagógico, que passa a atuar tendo como principais ferramentas a avaliação e o monitoramento educacionais.

O uso formativo da avaliação pareceu contemplado em iniciativas escolares informais destinadas à verificação do andamento do ensino e aprendizagem, com vistas a intervençóes imediatas orientadas para os objetivos estabelecidos.

\section{Considerações finais}

A política/gestão do ensino fundamental nas redes escolares municipais observadas resulta de complexos processos locais que envolvem condiçóes, restriçôes, visões, escolhas e procedimentos engendrados nas múltiplas inter-relações. Nesse contexto, se estabelecem as relações entre Município e União que são mediadas pela avaliação de resultados e monitoramento de metas de melhoria do ensino. Essa complexidade nos permitiu apreender somente alguns traços da realidade.

As redes escolares municipais se valem de duas estratégias ante a ação avaliativa e de monitoramento da Uniāo: a de incorporaçâo seletiva de itens da avaliação nacional segundo critério de utilidade; a de tentativas de construção de iniciativas próprias de avaliação que, com exceção de uma rede, se mostraram improvisadas, ensaísticas, exploratórias, episódicas.

Quando positivos, os resultados da avaliação e do Ideb são usados para fins de publicidade da atuação educacional do governo municipal e de emulação da rede e das unidades escolares mais bem sucedidas nas avaliaçôes. Frequentemente os resultados positivos são divulgados como expressão de chancela do governo federal ao governo municipal. Processo similar ocorre no âmbito da unidade escolar, onde os resultados são tomados como aval da atuação dos gestores escolares. No entanto, neste âmbito, a emulação pareceu ser o uso mais frequente. Os resultados positivos também são usados para o estreitamento de relaçóes entre Secretarias de Educação e unidades escolares e entre escola e comunidade.

Quando negativos, os resultados da avaliação e do Ideb são usados pelas Secretarias de Educação para pressionar os profissionais da escola por melhores resultados, para justificar suas intervençóes, para intensificar o monitoramento de resultados bimestrais, semestrais, anuais. No âmbito da escola, os resultados negativos são geralmente rejeitados ou ignorados e, quando não, ocasionam tensão nas relaçóes intraescolares, entre a escola e pais, entre a escola e a Secretaria de Educação. 
Sejam negativos ou positivos, os resultados são pouco estudados. A tecnologia de avaliação e de monitoramento nacionais não só é minimamente conhecida - havendo confusóes sobre as peculiaridades de cada iniciativa da União - como não tem sido objeto de atenção. Concorrem para isso reservas existentes nas redes em relação às iniciativas nacionais, que teriam caráter padronizador e, por isso, seriam incapazes de levar na devida conta as peculiaridades das diferentes realidades, ensejando comparaçóes falsas e injustas.

Para os dirigentes e os gestores, somente os atores locais são conhecedores das peculiaridades de seu contexto e de suas reais necessidades e possibilidades educacionais. Logo, somente as redes escolares poderiam realizar avaliaçóes adequadas e consequentes. Mas, para isso, precisam que a União, além de melhorar o financiamento educacional, assegure as condições técnicas necessárias, pois realizar avaliaçóes próprias propiciaria ao Município não só o legítimo como o producente exercício de sua autonomia.

Mediante incorporação e/ou construção de iniciativas próprias as redes da amostra tendem a reproduzir a lógica das iniciativas nacionais, prevalecendo usos de resultados das avaliaçóes associados à regulação e indução, sendo mínimo o uso formativo e para diagnóstico e inexistindo usos para prestação de contas públicas.

Em 90\% dos casos as iniciativas próprias de avaliação são incipientes e reproduzem a lógica da centralidade dos resultados, do gerencialismo, da redução do currículo ao que é mensurável e aos componentes curriculares Língua Portuguesa e Matemática.

Melhorar os resultados nas provas e no Ideb aparecem como prioridade da política/gestão municipal e da atuação da unidade escolar. Vemos nisso uma peculiar forma de cooperação do Município com a União: amálgama de constrangimento, assentimento e recusa, porém sem que os esforços municipais deixem de convergir para que a política nacional de melhoria da qualidade do ensino fundamental avance na direção sinalizada pelo governo federal.

Assim, as respostas municipais às iniciativas nacionais de avaliação e monitoramento se dão mediante cooperação e tentativas de preservação da autonomia municipal. De todo modo, difundem a racionalidade das políticas e avaliações educacionais nacionais.

\section{Notas}

1. A busca de aperfeiçoamento da avaliação e da criação de condiçóes para o monitoramento da educação básica no país teve passo importante com a Portaria n. 931, de 2005, pela qual o Saeb passa a ser composto por dois instrumentos: (1) a Prova Brasil, que se destina a avaliar o desempenho 
cognitivo dos alunos do ensino fundamental ( $4^{\mathrm{a}}$ série $/ 5^{\circ}$ ano e $8^{\mathrm{a}}$ série $/ 9^{\circ}$ ano) de escolas públicas urbanas; (2) a Avaliação Nacional da Educação Básica (Aneb) que, mantendo as características do Saeb (BONAMINO, 2002), propicia a avaliação de sistemas de ensino e acaba divulgada com o nome Saeb. A Prova Brasil, com sua metodologia quase censitária, oferece médias de desempenho para Brasil, regiôes, unidades da federação e municípios em nível de redes e sistemas de ensino, escolas e turmas, possibilitando a avaliação externa do desempenho das escolas participantes e oferecendo dados para o monitoramento do ensino. Para isso, utiliza todo o instrumental do Saeb e juntamente com este procede a aferiçóes bienalmente. Os dois instrumentos avaliam resultados quantificáveis do ensino, operando como ferramentas de regulação por resultados cujos riscos e problemas são objetos de críticas na literatura educacional, entre outros, nos trabalhos de Sousa (1997), Sousa; Oliveira (2003), Sousa; Freitas (2004), Freitas (2005; 2011; 2012), Gatti (2012).

2. Tratamos mais adiante desse Índice sobre o qual podem ser obtidas mais informaçôes de ordem técnica em Fernandes (2007).

3. Este trabalho é um recorte temático de investigação vinculada ao estudo realizado em redes escolares municipais destaques no Índice de Desenvolvimento da Educação Básica (Ideb) nos estados de São Paulo, Mato Grosso do Sul e Ceará, nos anos de 2009 e 2010. Intitulado "Bons resultados no Ideb: estudo exploratório de fatores explicativos". O estudo envolveu equipes de pesquisadores da USP, UFGD e UECE e contou com financiamento da Capes/Inep/Programa Observatório da Educação.

\section{Referências}

ABRUCIO, F. L. Para além da descentralização: os desafios da coordenação federativa no Brasil. In: FLEURY, S. Democracia, descentralização e desenvolvimento: Brasil e Espanha. Rio de Janeiro: Editora FGV, 2006. cap. 2, p. 76-125.

ANTUNES, J.; VIVIAN, D. M. Plano de Açóes Articuladas (PAR) do Município de Santa Maria RS: reflexôes possíveis. In: ENCONTRO NACIONAL DE DIDÁTICA E PRÁTICA DE ENSINO, 15, 2010, Belo Horizonte. Anais... Belo Horizonte: Endipe, 2010 .

BARRETTO, E. S. de S. A avaliação na educação básica entre dois modelos. Educ. Soc., Campinas, Cedes, n. 75, p. 48-66, ago. 2001.

BATISTA, N. C. Gestâo Democrática da Educação: um estudo de situações e tendências no Plano de Açôes Articuladas em Municípios do Rio Grande do Sul. In: SIMPÓSIO BRASILEIRO DE POLÍTICA E ADMINISTRAÇÃO DA EDUCAÇÃO, 25; CONGRESSO IBERO-AMERICANO DE POLÍTICA E ADMINISTRAÇÃO DA EDUCAÇÃO, 2., 2011, São Paulo, Anais... Recife: ANPAE, 2011.

BARROSO, J. O Estado, a educação e a regulação das políticas públicas. Educ. Soc., Campinas, v. 26, n. 92, p. 725-751, Especial, out. 2005.

BONAMINO, A. C. de. Tempos de avaliação educacional: o SAEB, seus agentes, referências e tendências. Rio de Janeiro: Quartet, 2002.

BRASIL. Decreto 6.094/07 de 24 de abril de 2007. Dispóe sobre a implementação do Plano de Metas Compromisso Todos pela Educação, pela União Federal, em regime de colaboração com Municípios, Distrito Federal e Estados, e a participação das famílias e 
da comunidade, mediante programas e ações de assistência técnica e financeira, visando a mobilização social pela melhoria da qualidade da educação. Diário Oficial da União. Brasília. DF, 25 abr. 2007.

BRASIL. Projeto de lei $n^{\circ}$ 8.035/2010. Aprova o Plano Nacional de Educação para o decênio 2011-2020, e dá outras providências. Brasília: Senado, 2010. Disponível em: <http:// www.senado.org.br>. Acesso em: 02 jan. 2012.

. Portaria no 931 de 21 de março de 2005. Institui o Sistema de Avaliação da Educação Básica - SAEB, que será composto por dois processos de avaliação: a Avaliação Nacional da Educação Básica - Aneb, e a Avaliação Nacional do Rendimento Escolar ANRESC. Diário Oficial da Uniáo, Brasília, DF., 22 de março de 2005. Disponível em: $<$ http://www.inep.gov.br/saeb/2005>. Acesso em: 02 jan. 2012.

BRESSOUX, P. Efeito estabelecimento. In: ZANTEN, A. V. (Coord.). Dicionário de educação. Petrópolis, RJ: Vozes, 2011, p. 275-279.

CONFEDERAÇÃO NACIONAL DOS MUNICÍPIOS. Disponível em: < http://www. cnm.org.brl>. Acesso em: 02 jun. 2010.

CURY, C. R. J. Sistema nacional de educação: desafio para uma educação igualitária e federativa. Educ. Soc., Campinas, v. 29, n. 105, p. 1187-1209, set./dez. 2008.

CRUZ, R. E. da. Federalismo e educação: um pacto a se rever. Revista Retratos da Escola, Brasília, v. 6, n. 10, p. 65-78, jan./jun. 2012.

DALE, R. A sociologia da educação e o Estado após a globalização. Educ. Soc., Campinas, v. 31, n. 113, p. 1099-1120, out./dez. 2010.

DOURADO, L. F. Plano Nacional de Educação como política de Estado: antecedentes históricos, avaliação e perspectivas. In: DOURADO, L. F. (Org.). Plano Nacional de Educação (2011-2020): avaliação e perspectivas. 2. ed. Goiânia: UFG; Belo Horizonte: Autêntica, 2011. p. 17-59.

DURLI, Z.; NARDI, E. L.; SCHNEIDER, M. P. Políticas de Formação e valorização dos professores da educação básica: (in)consistências das ações e estratégias do PAR nos municípios. In: REUNIĀO ANUAL DA ASSOCIAÇÃO NACIONAL DE PÓS-GRADUAÇÃO E PESQUISA EM EDUCAÇÃO, 34., 2011, Natal. Anais... Rio de Janeiro: ANPEd, 2011.

FAREZENA, N.; SCHUCH, C. C. T.; MOSNA, R. M. P. Implementação do Plano de Ações Articuladas em municípios do Rio Grande do Sul: uma avaliação. In: SIMPÓSIO BRASILEIRO DE POLÍTICA E ADMINISTRAÇÃO DA EDUCAÇÃO, 25; CONGRESSO IBERO-AMERICANO DE POLÍTICA E ADMINISTRAÇÁO DA EDUCAÇÃO, 2., 2011, São Paulo. Anais... Recife: ANPAE, 2011.

FERNANDES, R. Índice de Desenvolvimento da Educação Básica (Ideb). Brasília: Instituto Nacional de Estudos e Pesquisas Educacionais Anísio Teixeira, 2007.

FREITAS, D. N. T. de. A avaliaçáo da educação básica no Brasil: dimensão normativa, pedagógica e educativa. 2005. 289p. Tese (Doutorado em Educação) - Faculdade de Educação, Universidade de Sáo Paulo, Sáo Paulo. 
FREITAS, D. N. T. de. A avaliação na educação básica brasileira: tensões e desafios. Campo Grande, Revista Série Estudos, n. 33, 2012.

FREITAS, L. C. Responsabilização, meritocracia e privatização: conseguiremos escapar ao neotecnicismo? In: SEMINÁRIO DE EDUCAÇÃO BRASILEIRA. 3., 2011, Campinas. Anais... Campinas: Cedes, 2011, p. 1-35.

GATTI, B. A. Avaliação educacional no Brasil: pontuando uma história de açôes. Revista Eccos, v. 4, n. 1, p. 17-41, jun. 2002.

. Avaliação e qualidade da educação. In: SIMPÓSIO BRASILEIRO, V CONGRESSO LUSO-BRASILEIRO. 23.; COLÓQUIO IBERO-AMERICANO DE POLÍTICA E ADMINISTRAÇÃO DA EDUCAÇÃO. 1. 2007. Porto Alegre. Anais... Porto Alegre: Anpae, 2007. Disponível em: <http://www.anpae.org.br/congressos antigos/simposio2007/51.pdf >. Acesso em: 02 jan. 2012.

- Avaliação de sistemas educacionais no Brasil. Sísifo. Revista de Ciências da Educação, n. 9, p. 7 18, 2009. Disponível em: <http://sisifo.fpce.ul.pt >. Acesso em: janeiro 2012.

IBGE. INSTITUTO BRASILEIRO DE GEOGRAFIA E ESTATÍSTICA. Cidades. Disponível em: <http://www.ibge.gov.br>. Acesso em: 03 dez 2010.

INEP. INSTITUTO NACIONAL DE ESTUDOS E PESQUISAS EDUCACIONAIS "ANÍSIO TEIXEIRA". Índice de Desenvolvimento da Educação Básica. Brasília: MEC/ Inep, 2012. Disponível em: <http://www.ideb.inep.gov.br>. Acesso em: 02 jan. 2012.

JESSOP, B. A globalização e o Estado nacional. Crítica Marxista, n. 7, p. 9-45, 1998.

JOBERT, B.; MULLER, P. L'etat en action: politiques publiques et corporatismes. Paris: Puf, 1987.

LIMA, L. C. Modelos organizacionais de escola: perspectivas analíticas, teorias administrativas e o estudo da ação. In: MACHADO, L. M.; FERREIRA, N. S. C. (Orgs.). Política e gestão da educação: dois olhares. Rio de Janeiro: DP\&A, 2002. p. 33-53.

LIMA, S. E. A política educacional em municípios com bons resultados no Ideb: mapeamento de características. 2011. 149p. Dissertação (Mestrado em Educação), Universidade Federal da Grande Dourados. Dourados, 2011.

MORAES, R. C. C. de. As incomparáveis virtudes do mercado: políticas sociais e padróes de atuação do Estado nos marcos do neoliberalismo. In: CRAWCZYK, N.; CAMPOS, M. M.; HADDAD, S. (Orgs.). O cenário educacional latino-americano no limiar do século XXI - reformas em debate. Campinas: Autores Associados, 2000. p. 13-42.

MÜREKKEP. Globalização, regionalização, mercado e o Estado: entrevista com Bob Jessop. Ankara, Currículo sem Fronteiras, v. 2, n. 2, p. 5-21, jul./dez. 2002.

OLIVEIRA, R. P. Da universalização do ensino fundamental ao desafio da qualidade: uma análise histórica. Educ. Soc., v. 28, n. 100, p. 661-690, Especial, out. 2007. 
OVANDO, N. G. A avaliação na política educacional de municípios sul-mato-grossenses. Dissertação (Mestrado em Educação). Universidade Federal da Grande Dourados, Dourados, 2011.

PALUMBO, D. J. A abordagem de política pública para o desenvolvimento político na América. In: PALUMBO, D. J. Politica de capacitação dos profissionais da educação. Belo Horizonte: FAE/IRHJP, 1989. p. 35-61. [Original: PALUMBO, D.J. Public Policy in América. Government in Action. 2. ed. Tradução: Adriana Farah. Harcourt Brace \& Company, 1994. Cap. 1, p. 8-29].

PROGRAMA DAS NAÇÓES UNIDAS PARA O DESENVOLVIMENTO. Atlas do Desenvolvimento Humano. Brasília: Pnud, 210. Disponível em: <http://www.pnud.org. br>. Acesso em: 11 nov. 2009

SAMMONS, P. As características-chave das escolas eficazes. In: SAMMONS, P.; BROOKE, N.; SOARES, J. F. (Orgs.). Pesquisa em eficácia escolar: origem e trajetórias. Belo Horizonte: Editora UFMG, 2008.

SAVIANI, D. Organização da educação nacional: Sistema e Conselho Nacional de Educação, Plano e Fórum Nacional de Educação. Educ. Soc., v. 31, n. 112, p. 769-787, jul. I set. 2010.

REYNOLDS, D; TEDDLIE, C. Os processos da eficácia escolar. In: SAMMONS, P.; BROOKE, N.; SOARES, J. F. (Orgs.). Pesquisa em eficácia escolar: origem e trajetórias. Belo Horizonte: Editora UFMG, 2008.

SOUSA, S. M. Z. L. Avaliação do rendimento escolar como instrumento de gestão educacional. In: OLIVEIRA, D. A. (Org.). Gestão democrática da educação: desafios contemporâneos. Petrópolis: Vozes, 1997. p. 264-283.

. Possíveis impactos das políticas de avaliação no currículo escolar. Cadernos de Pesquisa, n. 119, p. 175-190, julho/ 2003.

SOUSA, S. M. Z. L.; OLIVEIRA, R. P de. Políticas de avaliação da educação e quase mercado no Brasil. Campinas, Educ. Soc., v. 24, n.84, p. 873-895, 2003.

SOUSA, S. M. Z. L.; FREITAS, D. N. T. de. Políticas de avaliação e gestão educacional - Brasil, década de 1990 aos dias atuais. Belo Horizonte, Educação em Revista, n. 40, p. 165-185, dez. 2004.

THERBORN, G. Dimensôes da globalização e a dinâmica das (des)igualdades. In: GENTILI, P. (Org.). Globalização excludente - desigualdade, exclusão e democracia na nova ordem mundial. 2. ed. Petrópolis: Vozes, 2000, p. 63-95.

ZACHER, M. W. Os pilares em ruína do templo de Vestfália: implicaçóes para a governança e a ordem internacional. In: ROSENAU, J. N.; CZEMPIEL, E. (Orgs.). Governança sem governo: ordem e transformação na política mundial. Brasília: UnB, 2000.

Recebido em 23 de novembro de 2012.

Aprovado em 23 de outubro de 2015.

DOI: $\underline{\text { http://dx.doi.org/10.1590/ES0101-7330201580647 }}$ 